\title{
Changing 8-9 Year-Old Pupil's Mental Representations of Light: A Metaphor Based Teaching Approach
}

\author{
James Rodriguez ${ }^{1} \&$ David Castro $^{1}$ \\ ${ }^{1}$ Primary Education, Denver, Colorado, USA \\ Correspondence: James Rodriguez, Denver, Colorado, USA. E-mail: jamerodr@gmail.com
}

Received: January 23, 2016

Accepted: January 27, 2016

Online Published: February 29, 2016

doi:10.20849/aes.v1i1.30

URL: http://dx.doi.org/10.20849/aes.v1i1.30

\begin{abstract}
This research paper examines the role that teaching mediation plays in the destabilization and reconstruction of representations of the concept of light among primary education students. It investigates their comprehension of light as an entity that is transferred autonomously of the light source and the receiver. This problem has been studied with two groups of 8-9 year-old children. The experimental group (E.G) participated in a teaching process that aimed to lead pupils to the construction of a model compatible to the scientific own; the control group (C.G) followed traditional teaching methods. In all experimental situations studied the difference between pre-test and post-tests was significant for the subjects of the experimental group both at the level of explaining the light as independent entity and at the level of the stability of cognitive acquisitions.
\end{abstract}

Keywords: primary education, science education, light, pupils’ representations, metaphor

\section{Introduction}

\subsection{Children's Representations of the Physical World}

Pupil's thought, about of concept and phenomena mental representations of the physical world, has previously been widely considered in the framework of Physics Education and/or Science Pedagogy (Driver, Guesne, \& Tiberghien, 1985; Driver, Squires, Rushworth, \& Wood-Robinson, 1994). Yet it has been realized that justifications concerning to pupils' conceptions about light is not harmonious with Physics models and theories. For an educational point of view this emphasizes the necessity for organizing appropriate teaching interventions for achieving conceptual change (Posner, Strike, Hewson, \& Gertzog, 1982; Carey, 1985; Hashweh, 1986).

For this purpose we studied pupil's mental representations of light as well as their change after a teaching procedure based on the use of a metaphor from everyday life (Jeppsson, Haglund, Amin, \& Stromdahl, 2013; Lancor, 2013). The model of Geometrical Optic, the classic model of Optics in Physics, provides the framework to identify and discussing these representations and assumes that light is an autonomous entity independent of the sources and the effects caused when it interacts with matter.

\subsection{The Piagetian Concept of Transitive Thought and the Light}

A starting point of our study is Piaget's (1971) assertion that transitive thought (if $A \rightarrow B$ and $B \rightarrow C$, then $A \rightarrow C$ ), although logico-mathematical in nature, can nevertheless be expanded so as to be applicable to physical entities like power, energy, heat or light as an indirect natural transition. This quality of thought Piaget calls "operational transitivity". Indeed, for a pupil at the pre-operational thought stage, the light is recognized on visible lighted areas (VLA) and light sources (LS) or both via a reasoning of direct transition of the following form: LS $\rightarrow$ VLA. Consequently, at this stage, child does not recognize the space in which light beams transmit, that is to say, the space of light's propagation (SPL). But, a particular form of mathematical transitivity featuring operational thought: LS $\rightarrow$ SPL and SPL $\rightarrow$ VLA $\rightarrow$ LS $\rightarrow$ VLA (Ravanis, Papamichaël, \& Koulaidis, 2002; Ravanis, 2012).

Therefore, according to Piaget (1971) in the framework of natural transition, the connection among the elements of the phenomenon of light propagation operates as a general scheme of representation about light. The mental representation of light based on transitivity is significant because, as a two-step procedure, requires determining the presence of light in the space. The recognition of light as an entity transmitted autonomously from the source to the receiver creates an essential convention and a necessary condition for understanding other phenomena as the formation of shadows, the reflection and the refraction or the notion of a straight path of light . 


\subsection{Describe Relevant Scholarship}

The problem of the difficulty of constructing light as an independent entity that propagates in space has previously been identified in a series of studies from 5 - 16 year-old students. Thus it seems that childrens' thought focuses more on light sources or bright areas where light arrives (Stead \& Osborne, 1980; Tiberghien, Delacote, Ghiglione, \& Matalon, 1980; Anderson \& Kärrqvist, 1983; Guesne, 1984, 1985; Langley, Ronen, \& Eylon, 1997; Rice \& Feher, 1987; Ravanis, 1998; Toh, Boo, \& Woon, 1999; Mendoza Pérez \& López-Tosado, 2000; Galili \& Hazan, 2000; Ravanis \& Boilevin, 2009; Ravanis, 2010; Castro, 2013; Castro \& Rodriguez, 2014; Grigorovitch, 2015).

Then, particular teaching interventions were planned using processes of specialized teaching interactions, through which the educational milieu can help the pupils construct the mental representations which they do not have or transform in their thought representations that are mismatched with the scientific own (Osborne, Black, Meadows, \& Smith, 1993; Ravanis \& Papamichaël, 1995; Dumas Carré, Weil-Barais, Ravanis, \& Shourcheh, 2003; Grigorovitch, 2014). In this research, a constructivist teaching strategy using a metaphor can help children create a scheme of thought harmonious to the scientific own in order to understand the concept of light. More specifically such a strategy can help children recognize light as an entity in space autonomous of sources and its corresponding effects.

\subsection{Hypotheses}

Therefore we suppose that pupils that have participated in experimental procedures based on a metaphor will be able to overcome cognitive obstacles and make estimations compatible to scientific models more easily than subjects who have taken part in traditional empirical class activities concerning the concept of light.

\section{Method}

\subsection{Research Design}

Creating a special teaching intervention, we have tried to change pupil's mental representations about light and leading children construct a model for the understanding of the concept of light compatible to the scientific own. More specifically, we have tried to help children move from pre-operational thought towards operational thought based on the Geometrical Optics model. The destabilization of representation was attempted through a metaphor/image from everyday life. According to Ravanis, Papamichaël and Koulaidis (2002), Ravanis, Christidou, and Hatzinikita (2013), an appropriate metaphor for the understanding of light is the concept: "travel of light in space". The metaphor of "travel" appears in the communication with the children as a result of the researcher's intervention during the experimental procedures and is connected with an object's displacement in space.

In specific, after a pilot exploration, our experimental design consisted of three phases: (a) pre-intervention data collection; (b) teaching intervention; (c) post-intervention data collection. During both pre and post-tests children were asked questions concerning the three tasks.

Regarding the pre-intervention and post-intervention phase our data of pupil's mental representations were collected through individual interviews. The average duration of these interviews was 12 minutes and took place in in a specially designed room. The data analysis was based on the transcribed interviews as well as on individual protocols of the particular recording of nonverbal behaviors. During the interview we asked the children to tell us where there is light in the tasks and to explain their thoughts. This was done for all three tasks. The pre-test was held two months in advance the instructions. The post-tests were held two and four months afterward instructions.

The intervention in the experimental group aimed to create conditions that could induce the pupil's thought to make the metaphor operational. Two months after the pre-test, a researcher from our team conducted the intervention with groups of 3-5 children. The duration of the teaching process was the same as the teaching of light in the original primary classroom settings.

On the basis of the scheme source-receiver, we presented the scheme source-space of diffusion and space of diffusion-receiver to the E.G. Here we tried to shift subject concentration from a scheme focused on the source or the receiver to another scheme in which light is recognized as an independent entity. With this aim, we asked the E.G. two questions: a) "Where the light comes to us?" and b) "How the light come to us?" Discussing with the children their answers, we presented the characteristics of the school adapted Geometrical Optics model adding the metaphor of light "travel" in space. We explicated that light comes from sources, like the sun or lamps. Sunlight travels through space going towards the Earth, the Moon, Mars, etc. We also analyzed the sunlight path to the earth through space and the atmosphere of clouds stating the terms "light", "rays" and 
"beams"; in addition we paint the pathway of light rays in space and in our everyday environment. Afterward, we presented a picture and a drawing from everyday life in which bundles of light are visibly accentuated. We asked them to explain this picture keeping in mind the light's absence in space. As a result, children's thought came to a dead-end. Then we are discussing again the "travel of light" concept and thus complete our teaching intervention.

The children of the Control Group attended a teaching intervention where an empiricist procedure was accurately took place. This teaching intervention was centered on the earth's light as coming from the sun. Then a discussion was held with children about the light from sources such as lamps and flashing lights. The role of the sun was fully analyzed and some details were given about the sun as light source. Additionally, the use of light sources was explained and the difference between self-lit and hetero-lit articles was presented. The whole procedure was based on a rich educational material of schemes and images where light's presence in the whole space in the form of light bundles is recorded. In other words, light is looked for in the air.

Therefore, the difference between this procedure and the teaching intervention in the E.G. consisted of an absence of the metaphor of "travel", the unified figure connection of both the points of departure and arrival as well as the traveling distance made via matter.

\subsection{Participants}

160 subjects ( 78 boys and 82 girls) from 8 to 9 years of age (average age 8.44 ) from 10 different primary school classes participated in this research. These classes were in the vicinity of certain Denver districts; thus they shared similar sociological features. The children were randomly separated in two equal groups of 80 children each; the experimental group and control group respectively.

\subsection{Tasks}

All tasks are designed to create the conditions which allow concentration on all three points: on light's sources, on lighted surfaces or on diffused light in space. By doing so, we considered that pupils can detect light in space independent of its sources. If this happens it seems that children go beyond their concentrations, use a transitional schema of thought and thus are able to construct models compatible to scientific concepts of light.

Task 1: In a room there are light rays from the sun, and electric lights on. We asked the children to show us, at least, three points in space having light. Subsequently, we asked the children to give as many responses as possible. In this way, we would be able to carefully confirm, whether or not they recognized the presence of light as an independent entity in space.

Task 2: We focused a straight beam of light from an electric torch towards a wall from a small distance. This way we create a visible bright spot on the wall. While the torch was on, we asked the children: "Where is there light from the torch?" In the case that the subject only answered 'the lit spot and/or the torch's lamp', we once more indicated the space in-between the torch and wall, which is a non-visible during the light of day to avoid a perceptive focus. We then asked: "Here in the air, is there any light between the torch and the surface of the wall?" Therefore the recognition of light in the air is reasonable to connect to the transitive thought.

Task 3: We set two vertical cardboard cards (A and B) on a constant flat base. On one card, a circular hole was cut out. Opposite the hole we had put a small lamp (L).

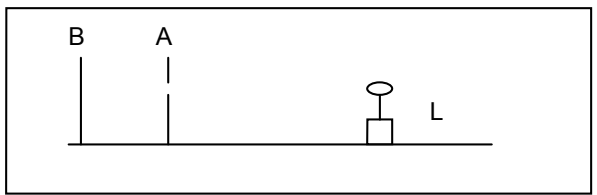

Figure 1. The two cardboards and the lamp (Task 3)

When the set was presented to the students, we turned on the light and asked, "Between the two cardboards there is light from the lamp?" If the answer was affirmative we ask the child to explain what he thinks about it. If the child's reasoning was not sufficient or the answer was negative, showing the air between the two cardboards, we were to ask: "Here in the air, is there any light from that lamp?"

For the last task, we chose this experimental situation because, in contrast with the first and the second task, it is not from an everyday life condition. The light ray of the lamp was not visible due to the intensity from light their vicinities. 


\subsection{Criteria of Evaluation}

The scale we used for checking the changes that appeared between the answers of the two groups of children in the pre-test and post-tests includes two levels: progress and immobility. We estimate progress as the transition from pre-operational explanations to operational level explanations. Therefore, this is a transition from answers of concentration to explanations based on the recognition of light as an independent entity in the air. We estimate immobility as being the persistence on the same responses in both the pre-test and post-tests.

\section{Results}

An appropriate statistical control (the Mann-Whitney test) was applied in order to found whether the differences between two independent samples coming from the same population were statistically significant or not. We estimate the differences between the two groups statistically important at a 0.05 level of significance.

In all tasks the answers given are based on the same mental representation and are classified in the same two categories, in both the pre-test and post-tests (Table 1).

The analysis showed the following:

a) The presence of light in space, which means in spaces where light is not visible, is recognized in answers based in an operational scheme of thought. For example, "Here where we stand upright ........beside .........almost everywhere in the room...." (Task 1). "On the wall opposite and in the light's path..." (Task 2). "On the wall, the light passes through the space...... and..... and.... is light there... (the children shows the direction of light)" (Task 2). "There is the light... from the lamp to the space...it passes through the space... but we cannot see it" (Task 3).

In the first task, the responses of this category are the following: the pre-test was 2 for the subjects of the E.G., while the C.G. was 3. In the second task, the answers in the pre-test were 20 and 19 respectively. In the third task, the pre-test was 14 and 15 correspondingly.

b) The light's existence in points where there are visible spots lit by light bundles and/or in the light sources is recognized by the answers of pre-operational thought. "Over the wall light shines ...." (Task 1). "On the window... there is light in the flashlight..... in the lamp....." (Task 2). "There is no light because ....... because it goes through the hole .... and.... and go over there .... it does not go there (to the space)" (Task 3). During the pre-test the E.G. answers for this category were 78 for the first task, 60 for the second and 66 for the third task. The answers of the C.G. were 77, 61 and 65 respectively.

Table 1. Frequencies of experimental and control group subjects' answers in three tasks

\begin{tabular}{llllllll}
\hline & & \multicolumn{2}{c}{ PRE-TEST } & \multicolumn{2}{c}{ A POST-TEST } & \multicolumn{2}{c}{ B POST-TEST } \\
& & E. G. & C. G. & E. G. & C. G. & E. G. & C. G \\
\hline \multirow{2}{*}{ Task 1 } & Cat. A & 2 & 3 & 46 & 12 & 48 & 12 \\
& Cat. B & 78 & 77 & 34 & 68 & 32 & 68 \\
\multirow{2}{*}{ Task 2 } & Cat. A & 20 & 19 & 48 & 25 & 50 & 27 \\
& Cat. B & 60 & 61 & 32 & 55 & 30 & 53 \\
\multirow{2}{*}{ Task 3 } & Cat. A & 14 & 15 & 53 & 19 & 56 & 21 \\
& Cat. B & 66 & 65 & 27 & 61 & 24 & 59 \\
\hline
\end{tabular}

Table 2 shows the changes between the pre-test to post-tests in the answers of both E.G. and C.G. children.

The modifications in the children' estimations seem to verify our hypothesis. In the first task for both the post-tests, the E.G. children showed more progress than those of the C.G. The differences between them are significant (task 1, 1st post-test: $\mathrm{U}=2232, \mathrm{p}<0.001$, 2nd post-test: $\mathrm{U}=2005 \mathrm{p}<0.001$ ). In the second task, the difference is statistically significant for the first post-test $(\mathrm{U}=2882, \mathrm{p}<0.023)$ and for the second post-test $(\mathrm{U}=2756, \mathrm{p}<0.017)$. In the third task, the changes in the answers between the post-test and pre-test seem to confirm our hypothesis (task 3, 1st post-test: $U=2456, p<0.002$, 2nd post-test: $U=2354, p<0.002$ ).

From the presented results, we can conclude that the children of the E.G. group are capable to identify light as an entity in air more than that of the C.G. 
Table 2. Data of children's responses showing changes between pre- and post-tests

\begin{tabular}{llllll}
\hline & & \multicolumn{2}{l}{ PRE-TEST / A POST-TEST } & \multicolumn{2}{l}{ PRE-TEST / B POST-TEST } \\
& E.G. & C.G. & E.G. & C.G. \\
\hline \multirow{2}{*}{ Task 1} & Progress & 44 & 9 & 46 & 9 \\
& Immobility & 36 & 71 & 34 & 71 \\
\multirow{3}{*}{ Task 2 } & Progress & 28 & 6 & 30 & 8 \\
& Immobility & 52 & 74 & 50 & 72 \\
Task 3 & Progress & 39 & 4 & 42 & 6 \\
& Immobility & 41 & 76 & 38 & 74 \\
\hline
\end{tabular}

Consequently, relating to the first task, we observed an important progress in the responses of the E.G. as far as the recognition of light in an everyday situation is concerned. For both post-tests, it seems that the concentration on brightly lit areas or/and light sources declines. Two and four months after attending the teaching interventions several children of the E.G., were without difficulty able to show light in space.

In the second task, our hypothesis is confirmed in both post-test. In a procedure that is common in our everyday life, that is, the visual confirmation of light's existence along a torch bundle, the E.G. children showed progress. Nevertheless, it seems that the C.G. children who had attended a classical teaching intervention progressively understood the notion of light's existence in space. This may be attributed to the type of the task that leads to a situation where children have already formed static mental representations. Nonetheless, in each case, the progress of the E.G. was greater.

The validation of our hypothesis in the first and the second post-test of the third task is of great importance. Here we presented an unfamiliar situation for pupil experience. The E.G. children gradually succeeded in recognizing light in-between the two cardboards. This remark needs reasoning based on a mental scheme absolutely de-concentrated from the perceptible elements of the situation.

\section{Discussion}

In this paper, we attempted to show in a constructivist theoretical framework that the initiation of children 8-9 yers-old in some sides of the physical world is possible in the direction where primary school pupil's construct a model of thought compatible with the descriptive elements of geometrical optics model. The results of the research procedure allow us to claim that our hypotheses were confirmed. As we can see from our data, the children of the experimental group are able to recognize light as an independent entity more than that of the control group (Galili \& Hazan, 2000; Grigorovitch, 2014).

From our research there is evidence indicating the important role of a metaphor in the destabilization of spontaneous representations and the structuring of a model compatible to the scientific own for the light. Really, it seems efficient with this process, as an instrument of social interaction, to drive a pre-operational scheme of thought to an advanced level. Thus, after the teaching intervention with both groups we can detect for the three tasks that it was about 5-6 out of 10 children in the experimental group who made progress compared with less than one child in the control group. These results lead us to identify the important role of the teaching activities concerning interactions organised around the existing difficulties to pupil's intellectual development.

Regarding the role of the teacher, this seems to be of importance for all the activities that made children. This is so because not only do they organize the educational environment, but also they also methodically follow the reasoning of the pupils, intervening just at the points where these require support in order to overcome obstacles of a cognitive kind.

As was found, and according to relevant literature, the dynamics of the metaphor based communication between the teachers and the pupils favoured the intellectual progress of the latter (Ravanis, Papamichaël, \& Koulaidis, 2002; Ravanis, Christidou, \& Hatzinikita, 2013). Nevertheless, the general deployment of the activity with the pupils of the E.G. is far from the actual conditions in the primary school, no matter how interesting the results of this research. However if we find that pupil are able to approach the crucial factors of the problem, we can subsequently design teaching intervention, which progressively approach, the actual conditions in a primary school class. In such a study, which is now being completed, the interactions between a primary teacher and a small group of children seem to render interesting learning results. 
In every case though, the general theoretical approaches to learning as a product of social interactions lead to the improvement of teaching situations, which favor pupil's initiation in the properties of objects, the phenomena of nature and the concept of the physical sciences. From the perspective of children's whole development, we do not include simply organized activities for an early approaching the physical sciences, but we hope that these activities will prepare children for a better understanding at a later stage.

\section{References}

Andersson, B., \& Kärrqvist, C. (1983). How Swedish pupils aged 12-15 years understand light and its properties. European Journal of Science Education, 5(4), 387-402.

Castro, D. (2013). Light mental representations of 11-12 year old students. Journal of Social Science Research, $1(2), 35-39$.

Castro, D., \& Rodriguez, J. (2014). 8-9 year old pupils' mental representations of light: teaching perspectives. Journal of Advances in Natural Sciences, 2(1), 40-44.

Carey, S. (1985). Conceptual change in childhood. Cambridge: MA: MIT Press.

Driver, R., Guesne, E., \& Tiberghien, A. (1985). Children's ideas in science. Philadelphia: Open University Press.

Driver, R., Squires, A., Rushworth, P., \& Wood-Robinson, V. (1994). Making sense of secondary science research into children's ideas. London \& New York: Routledge.

Dumas, A., Weil-Barais, A., Ravanis, K., \& Shourcheh, F. (2003). Interactions maitre-élèves en cours d'activités scientifiques à l'école maternelle : approche comparative. Bulletin de Psychologie, 56(4).

Galili, I., \& Hazan, A. (2000). Learners' knowledge in optics: interpretation, structure and analysis. International Journal of Science Education, 22(1), 57-88. http://dx.doi.org/10.1080/095006900290000

Grigorovitch, A. (2014). Children's misconceptions and conceptual change in Physics Education: the concept of light. Journal of Advances in Natural Sciences, 1(1), 34-39.

Grigorovitch, A. (2015). Teaching optics perspectives: 10-11 year old pupils' representations of light. International Education \& Research Journal, 1(3), 4-6.

Guesne, E. (1984). Children's ideas about light. In E. J. Wenham (Ed.), New Trends in Physics Teaching (pp. 179-192). Paris: UNESCO.

Guesne, E. (1985). Light. In R. Driver, E. Guesne, \& A. Tiberghien (Eds.), Children's ideas in science (pp. 10-32). Philadelphia: Open University Press.

Hashweh, M. Z. (1986). Toward an explanation of conceptual change. European Journal of Science Education, $8(3), 229-249$.

Jeppsson, F., Haglund, J., Amin, T. G., \& Stromdahl, H. (2013). Exploring the use of conceptual metaphor in solving problems on entropy. Journal of the Learning Sciences, 22(1), 70-120. http://dx.doi.org/10.1080/10508406.2012.691926

Lancor, R. A. (2013). The many metaphors of energy: Using analogies as a formative assessment tool. Journal of College Science Teaching, 42(3), 38-45.

Langley, D., Ronen, M., \& Eylon, B. (1997). Light propagation and visual patterns: preinstruction learners' conceptions. Journal of Research in Science Teaching, 34(4), 399-424. http://dx.doi.org/10.1002/(SICI)1098-2736(199704)

Mendoza Pérez, A., \& López-Tosado, V. (2000). "Light" conceptualisation in children aged between 6 and 9. Journal of Science Education, 1(1), 26-29.

Osborne, J., Black, P., Meadows, J., \& Smith, M. (1993). Young children's ideas about light and their development. International Journal of Science Education, 15(1), 83-93. http://dx.doi.org/10.1080/0950069930150107

Piaget, J. (1971). Causalité et opérations. In J. Piaget, \& R. Garcia (Eds), Les explications causales (pp. 11-140). Paris: PUF.

Posner, G. J., Strike, K. A., Hewson, P. W., \& Gertzog, W. A. (1982). Accommodation of a scientific conception: Toward a theory of conceptual change. Science Education, 66(2), 211-227. http://dx.doi.org/10.1002/sce.3730660207 
Ravanis, K. (1998). Procédures didactiques de déstabilisation des représentations spontanées des élèves de 5 et 10 ans. Le cas de la formation des ombres. In A. Dumas Carré, \& A. Weil-Barais (Eds.), Tutelle et médiation dans l'éducation scientifique (pp. 105-121). Berne: P. Lang.

Ravanis, K. (2010). Représentations, Modèles Précurseurs, Objectifs-Obstacles et Médiation-Tutelle: concepts-clés pour la construction des connaissances du monde physique à l'âge de 5-7 ans. Revista Electrónica de Investigación en Educación en Ciencias, 5(2), 1-11.

Ravanis, K. (2012). Représentations des enfants de 10 ans sur le concept de lumière: perspectives piagétiennes. Schème - Revista Eletrônica de Psicologia e Epistemologia Genéticas, 4(1), 70-84.

Ravanis, K., \& Papamichaël, Y. (1995). Procédures didactiques de déstabilisation du système de représentation spontanée des élèves pour la propagation de la lumière. Didaskalia, 7, 43-61.

Ravanis, K., Papamichaël, Y., \& Koulaidis, V. (2002). Social marking and conceptual change: the conception of light for ten-year old children. Journal of Science Education, 3(1), 15-18.

Ravanis, K., \& Boilevin, J. M. (2009). A comparative approach to the representation of light for five-, eight- and ten-year-old children: educational perspectives. Journal of Baltic Science Education, 8(3), 182-190.

Ravanis, K., Christidou, V., \& Hatzinikita, V. (2013). Enhancing conceptual change in preschool children's representations of light: a socio-cognitive approach. Research in Science Education, 43(6), 2257-2276. http://dx.doi.org/10.1007/s11165-013-9356-z

Rice, K., \& Feher, E. (1987). Pinholes and images: children's conceptions of light and vision. Science Education, 71, 629-639. http://dx.doi.org/10.1002/sce.3730710413

Stead, B., \& Osborne, R. (1980). Exploring student's concepts of light. Australian Science Teacher Journal, $3(26), 84-90$.

Tiberghien, A., Delacote, G., Ghiglione, R., \& Matalon B. (1980). Conceptions de la lumière chez l'enfant de 10-12 ans. Revue Française de Pédagogie, 50, 24-41.

Toh, K. A., Boo, H. K., \& Woon, T. L. (1999). Students' perspectives in understanding light and vision. Educational Research, 41(2), 155-162. http://dx.doi.org/10.1080/0013188990410203

\section{Copyrights}

Copyright for this article is retained by the author(s), with first publication rights granted to the journal.

This is an open-access article distributed under the terms and conditions of the Creative Commons Attribution license (http://creativecommons.org/licenses/by/3.0/). 